\title{
A SENSAÇÃO DE MORRER NA DANZA GENERAL DE LA MUERTE
}

\section{The feelling of dying in the Danza General de la Muerte}

\author{
Juliana Schmitt \\ Doutora em Letras pela Universidade de São Paulo (USP), \\ Pós-doutorado em Artes, Cultura e Linguagens pela Universidade Federal de Juiz de Fora \\ (UFJF) \\ ORCID: https://orcid.org/0000-0001-5770-0436 \\ e-mail: juschmittju@gmail.com
}

Recebido em: 09/10/2020

Aprovado em: 10/01/2021

\begin{abstract}
Resumo: As danças macabras medievais configuram-se como uma elaboração iconográfica e poética do momento da morte. O fim da vida é representado pela chegada de um cadáver, ou da Morte, que carrega um vivo consigo. Cada vertente do gênero oferece diferentes configurações desse encontro, com variações tanto em seus elementos imagéticos quanto textuais. Nesse artigo, nosso foco concentra-se na Danza General de la Muerte, manuscrito em castelhano, provavelmente do século XV, pertencente ao acervo da Biblioteca do Mosteiro do Escorial, na Espanha. Analisaremos as reações de alguns de seus personagens diante da constatação de seu óbito e como os sintomas da degeneração física são percebidos e sentidos. Nos deteremos mais minuciosamente no personagem do Médico, que oferece maiores pistas em relação ao entendimento da época sobre os males que acometem o corpo. Deste modo, mesmo sem se referir a enfermidades específicas, é possível observar de que maneira se manifesta a chegada da morte no poema.
\end{abstract}

Palavras-chave: Danças Macabras; morte na Idade Média; Danza General de la Muerte.

Abstract: Medieval dances of death are configured as an iconographic and poetic elaboration of the moment of death. The end of life is represented by the arrival of a corpse, or by "Death" itself, which carries a living person with it. Each strand of the genre offers different configurations of this encounter, with variations in both its imagery and textual elements. In this article, our focus is on the Danza General de la Muerte, manuscript in old castilian, probably from the 15th century, from the collection of the Library of the Monastery of Escorial, in Spain. We will analyze the reactions of some of its characters on realizing their own death and how the symptoms of physical degeneration are perceived and felt. We will look more closely at the Phisician, who offers better clues about the understanding of the Medicine and how to deal with diseases. In this way, even without referring to specific illnesses, it is possible to observe how death and the feelling of dying appears in the poem.

Keywords: Dance of Death; death in the Middle Ages; Danza General de la Muerte. 


\section{Introdução}

"Yo só la muerte cierta a todas criaturas", diz a Morte ao se apresentar na Danza General de la Muerte. ${ }^{1}$ Este é o início de uma narrativa poética que colocará a ceifadora diante de personagens variados, entre clérigos e seculares, representantes de todos os estratos sociais. A cada um deles, ela se dirige de uma maneira, mas todos têm o mesmo destino: acompanhá-la em seu bailado, o que significa ir a óbito. Seja inesperada ou não, a chegada da Morte acontece com características diferentes: em alguns, pela sensação de desequílibrio, em outros, pela perda dos sentidos, em outros ainda, por inflamações ou dores lancinantes. Na Danza General de la Muerte, tão diversa quanta a gama de personagens é a forma como eles morrem.

O poema nunca deixa claro qual é exatamente o mal que acomete essas vítimas. Daí nosso interesse na leitura dessa obra tão particular. Ao colocar em cena personagens corriqueiros do cotidiano da Baixa Idade Média sendo confrontados com a Morte, é possível levantar alguns dos sintomas percebidos por essas figuras que as fazem sentir que estão morrendo. Nossa atenção nesse documento se justifica pelo dado historiográfico de que a época viu surgir uma concepção mais material da morte, uma consciência nova acerca da existência terrena, que a Danza General bem revela. É o reconhecimento da "morte de si mesmo", como Philippe Ariès denomina o fenômeno: "foi justamente no olhar que cada homem lançava sobre sua vida, no limiar da morte, que ele tomou consciência da particularidade de sua biografia e, consequentemente, da sua personalidade." (2003, p. 135). Para Alberto Tenenti, esse processo resultou em atitudes polarizadas diante da morte: a certeza da aniquilação física causava ora um apelo absoluto ao destino da alma, ora um amor imensurável à vida e o apego profundo às coisas terrenas $(1957$, p. 165). Antes dele, Johan Huizinga já afirmava que "o pensamento religioso do final da Idade Média, no que diz respeito à questão da morte, conhece apenas os dois extremos: o lamento pela perecibilidade, pelo fim do poder, da honra e do prazer, pela decadência da beleza; e, por outro lado, o júbilo da alma que foi salva." (2010, p. 243).

A Danza General de la Muerte é um poema em castelhano cujo registro mais antigo trata-se de um manuscrito pertencente ao acervo da Biblioteca do Mosteiro do Escorial, nas cercanias de Madri. Sobre esse documento (Ms. b. IV 21 - fólios 109r- 
129r), sabe-se muito pouco: não há data de sua escritura ou composição nem indicação de autoria. Desde sua doação ao monastério, foi acomodado com outros manuscritos e encadernados em um codex de miscelânia. Está escrito em letra gótica, em tinta preta e vermelha. Possui pequenas adições ou correções feitas posteriormente, não se sabe quando, em uma escrita muito delicada, quase imperceptível. Tudo indica que o texto seja a cópia de um original do qual não se tem nenhuma informação. ${ }^{2}$ É estruturado em 79 estrofes de 8 versos dodecassílabos, com rimas em ABABBCCB, além de um curto parágrafo de abertura, em prosa. Enfrentam a Morte, ao todo, 33 personagens.

Pesquisadores que se dedicaram ao seu estudo se debruçam em hipóteses relativas à sua datação. ${ }^{3}$ Não há concordância, mas deve-se considerar o fato da Danza General fazer parte do tema das danças macabras, o gênero literário e iconográfico surgido no fim da Idade Média, provavelmente no século XV. Seu primeiro registro documentado e datado é um afresco pintado em 1424, em um dos muros do cemitério dos Santos Inocentes, localizado no $1^{\mathrm{o}}$ arrondissement, em Paris. Ele decorava a parede interna de uma das galerias que funcionavam como ossário, espaço bastante acessível e que, por causa disso, deve ter sido visto por muita gente. Segundo Johan Huizinga, "a dança macabra do Cemitério dos Inocentes foi a imagem mais popular da morte que a Idade Média conheceu." (2010, p. 234)

A obra foi totalmente destruída em 1669, mas inspirou diversas cópias e versões. É por causa delas que é possível nos aproximarmos da configuração da original, que serviu de modelo para as demais: uma grande e extensa pintura mural que dispunha, em uma fileira, personagens vivos e mortos. Os vivos representavam figuras da sociedade medieval, alternando religiosos e laicos, começando dos mais poderosos aos mais humildes: cerca de 30, incluindo o papa, o imperador, o cardeal, o rei, o arcebispo, o cavaleiro, o abade, o burguês, o advogado, o médico, o padre, o menestrel, o monge, o camponês, o ermitão, a criança, entre outros. Os cadáveres que formam dupla com cada um deles aparecem em estado de decomposição, com a pele ressequida, restos de cabelos presos ao crânio, cavidades oculares vazias, ventre aberto, ossos à mostra, impregnados de vermes. O encontro entre eles é o derradeiro instante dos viventes. Os versos que acompanhavam a pintura propõem uma espécie de diálogo, em que os mortos chamam suas vítimas e elas respondem, reagindo à percepção de seu próprio fim de acordo com sua experiência de vida. 
A partir dessa primeira obra, de considerável repercussão, as danças macabras parecem ter se disseminado na forma de afrescos em igrejas e cemitérios por toda a cristandade, além de inúmeros manuscritos e iluminuras, se popularizando definitivamente no fim dos quatrocentos em forma de impressos. Esses exemplares possuem mais ou menos a mesma configuração, como exposto acima, com pequenas variantes: quantidade de personagens vivos, presença ou ausência dos versos, a maneira como vivos e mortos interagem, entre outras. O contexto sócio-cultural que dá origem às danças macabras na Baixa Idade Média, sua etimologia e toda a sua trajetória como tópica literária e imagética até o século XIX foi explorado por nós em publicação anterior. $^{4}$

O que nos importa, nesse momento, é retomar algumas das mensagens atribuídas às danças macabras. Elas ensinam, de maneira bastante didática, que a morte pode aparecer a qualquer momento e, por isso, é necessário estar preparado para sua chegada. Nesse sentido, remetem-se ao tema medieval da "boa morte". Mas, ao mesmo tempo que falam sobre a vanidade das coisas materiais, a inevitabilidade e universalidade da morte, poderiam representar também um lembrete da brevidade da vida e um convite a aproveitá-la enquanto há tempo: "Les danses macabres proclament à la fois la condamnation et l'exaltation du monde”, afirma Joël Saugnieux (1972, p. 98). Voltaremos a essa questão mais adiante.

Assim, apesar da incerteza quanto à datação do manuscrito da Danza General de la Muerte, pode-se considerá-la pertencente a esse desenvolvimento do gênero no século XV. ${ }^{5}$ Em 1520 ela ganha uma versão impressa, por Juan Varela de Salamanca, editor residente na cidade de Sevilha. Parece que apenas um exemplar dessa edição sobreviveu, e ficou por muito tempo guardado na Biblioteca de Alexandria. Hoje, está desaparecido. Em 1860, quando ainda estava na biblioteca e podia ser consultado, foi copiado a mão por Isidoro Lozano para J. Amador de los Ríos (por volta de 1860), que o incluiu em sua História crítica de la literatura española, publicada entre 1861 e 1865. Graças a esse esforço, o texto foi conhecido a partir do século XIX: trata-se do mesmo conteúdo da Dança General, aumentado para 139 estrofes e mais 23 personagens.

Logo no prólogo da Danza General de La Muerte, a Morte intima "a todos os estados do mundo que venham, de bom grado ou contra sua vontade". E se ela é "a Morte certa a todas as criaturas" (verso 1), isso não significa que cada uma delas é 
surpreendida da mesma maneira. Vejamos agora como suas vítimas reagem à sua chegada.

\title{
Sintomas físicos da chegada da Morte
}

Muito embora pertença ao gênero das danças macabras, a Danza General de la Muerte possui suas particularidades. Talvez a mais importante é tratar-se de uma dança da Morte, não dos mortos. A própria Morte personificada abre o poema apresentandose, e intervém na trajetória de cada vivente partícipe do bailado. Na primeira estrofe, ela já repreende o alto apreço que o homem consagra à vida que é tão breve e transitória. Também anuncia sua fúria, expressa pelas flechas que atira, das quais não podem fugir nem o mais forte e régio "gigante" - isto é, nem a maior autoridade, seja laica ou religiosa, está a salvo:

\author{
Yo só la Muerte cierta a todas criaturas \\ que son e serán en el mundo durante; \\ demando y digo: Oh homne! Por qué curas \\ de vida tan breve, en punto pasante? \\ Pues no hay tan fuerte nin recio gigante \\ que deste mi arco se puede amparar, \\ conviene que mueras, cuando lo tirar, \\ con esta mi frecha cruel, traspassante.
}

$\mathrm{Na}$ estrofe seguinte, ela reafirma sua impetuosidade, que derruba mesmo a pessoa de boa compleição física. Lembra que um corpo forte e saudável ainda é um corpo vil, que se desmanchará em corrupção, podridão e infecções. ${ }^{6}$ Aqui, o poema ecoa a estética macabra de sua época. Como já vimos, "La corrupción corporal fue un tema muy en voga en los siglos XIV y XV", recordam Hurtado e Cvitanovic (1966, p. 51). E Johan Huizinga recupera o surgimento da palavra "macabro" nos trezentos, "o adjetivo que para nós adquiriu uma nuance de significado tão nítido e próprio, a ponto de com ele podermos marcar toda a visão da morte do fim do período medieval" (2010, p. 231), termo que se convencionou associar com as representação do cadáver em decomposição.

A tônica é a mesma quando a Morte apresenta duas donzelas que a acompanham e às quais denomina suas "noivas", e se confunde com o tema da beleza feminina que 
fenece e que podemos encontrar abundantemente na Danse macabre des femmes, de 1486, de Guyot Marchant. ${ }^{7}$ Às suas noivas e a todas criaturas que leva desse mundo, a Morte promete, no lugar dos enfeites, a feiúra. No lugar das roupas, a nudez. E como morada eterna, ao invés de palácios, "sepulcros escuros de dentro fedientes" (v. 78). Substituindo os manjares que desfrutaram em vida, a Morte oferece os vermes roedores que comerão desde dentro suas carnes apodrecidas.

O Imperador, personagem da hierarquia secular mais importante da sociedade, entra na dança logo após o Papa, que abre o desfile. É ele o primeiro a se queixar dos efeitos corpóreos ao deparar-se com sua algoz: reclama de ser levado à força e não poder se defender por estar perdendo o juízo, ter "el seso turbado" (v. 112). O sintoma se repete em outros participantes. A Morte acusa o Abade de ser folgado e vicioso antes de "abraçá-lo" - e ele não escapa por já se sentir desatento. A estrofe do Deão começa com ele assustado por estar "saindo do eixo" e não conseguir fugir. Isto the parece um mau sinal, pois vê que preparam a cera para cobri-lo (como informam Hurtado e Cvitanovic [1996, p. 29], o trecho refere-se ao costume da "gente de qualidade" cobrir seus mortos com cera. Huizinga fala da preparação do cadáver para disfarçar as marcas da putrefação antes do enterro [2010, p. 230]). O Rabino, personagem que não se repete em nenhuma outra dança macabra além da Danza General, parece entender que está indo a óbito, pois, perde o discernimento e "com grande aflição" (v. 576), pede que seus companheiros cuidem dele. Por não ter se dedicado à "verdadeira" fé, a Morte o condena a sofrer "penas e dores".

Essa alteração dos sentidos é acompanhada, no caso do Rei, pela sensação de que o coração "se queixa com grandes gemidos", o que poderia indicar algum distúrbio cardíaco simultâneo à sensação de torpor. O Cardeal é dos que mais expressam incômodos físicos com a chegada da Morte: ele começa a tremer, sente todos os membros afetados, perde a vista e a audição. Em sua réplica, a Morte lhe diz que o fará “suar" em sua dança (v. 132). Também ao Advogado ela causa cegueira e, o que parece pior no caso deste, a mudez ("envolveu-me a morte, não consigo falar" [v. 336]). O Bispo indica sua aflição apertando as mãos e chorando de tanta tristeza, ao ver-se na iminência do fim. Não é à toa: a Morte diz que planeja esfolá-lo.

A súbita preocupação do Mercador ao deparar-se com a Morte é com suas riquezas e com suas mercadorias, que traz pelo mar para comercializar no continente. 
Zombeteira, ela o tranquiliza (ela parece ser especialmente cruel com o Mercador), dizendo que já não precisa mais ir à Flandres, uma menção interesante a um dos principais pólos econômicos da Baixa Idade Média, região famosa pelo comércio de têxteis de alta qualidade. Era, afinal, chegada a hora de tratar de outros negócios. A Morte convida-o a entrar em sua pequena lojinha, onde que cabe apenas um corpo deitado no chão; lá, the oferece "bubas y landres", bubões e tumores (v. 307): "de gracia las dó, non las quiero vender” (v. 308), gracejando com o ofício da vítima.

Assim, tudo indica que a causa de óbito do Mercador na Danza esteja relacionado a essas manifestações físicas inflamatórias. Possivelmente um dos maiores temores dos homens que testemunharam os dois últimos séculos medievais, o aparecimento de bubões remetia diretamente à doença que assolou a Europa a partir de 1347, a Peste Negra. O entumescimento das linfas era percebida como uma sentença de morte - ainda que essa sua forma mais comum, a peste bubônica, não fosse tão fatal quanto a penumônica e a septicêmica. Conforme descreve Jöel Saugnieux, "Ce qui est vrai, c'est qu'elle a profondément marqué les esprits. (...) Les malades étaient couverts de bubons, d'abcès, de plaies gangreneuses; ils étaient atteints d'hemmorragies et de troubles nerveux: vertiges, hallucinations, délire, coma." (1972, p. 95-6). Ou seja, além do aspecto repugnante, a doença aterrorizava pela aparente perda da sanidade.

É interessante que o padecente dos bubões seja justamente o Mercador, associado às atividades profissionais das cidades portuárias, primeiros lugares em que se registrou a presença da Peste Negra na Europa. Há de se ter em mente o papel crucial que comerciantes e mercadores desempenham nas teorias sobre o trajeto que a Yersinia pestis percorreu entre sua irrupção no Oriente e seu subsequente aparecimento nos portos do Mediterrâneo, locais movimentados, de grande trânsito e densidade populacional, fatores que certamente contribuíram para a propagação do mal. Joseph Byrne lembra que "though merchants were not the only ones to travel by ship - clerics, pilgrims, emissaries, soldiers, slaves and refugees did so as well - merchants and their cargoes probably played the largest role in transmitting ship-borne plague." (2012, p. 232, verbete "Merchants"). A Morte, portanto, usando de fina ironia, oferece bubões ao Mercador, fazendo com que morra da doença que teria ajudado a espalhar.

Não se pode esquecer que o vínculo entre os surtos de Peste Negra e o surgimento dos temas macabros é amplamente debatido entre os pesquisadores das 
danças. Não cabe ao escopo desse artigo levantar os pontos concordantes e conflitantes desse debate, queremos apenas considerar essa ameaça da Morte da Danza General em infligir bubões e tumores em um de seus condenados como uma sugestão da assiduidade dos surtos de Peste Negra, rondando periodicamente o cotidiano daquelas pessoas e possivelmente influenciando a produção das obras macabras. Victor Infantes resumiu a questão dizendo que:

\begin{abstract}
la presencia de la peste va a traer la evidencia física de la muerte, su realidad inamovible, su sobrecogedora constancia. El morir se convierte en un hecho cotidiano y habitual, asumido por todos y más inevitable que nunca. (...) La Muerte no será un concepto, un tema, un motivo; ahora es lo obvio, lo que todos observan impotentes y aterrados. Esta conciencia, esta familiaridad con el fenómeno macabro creo que tuvo que influir poderosamente en los artistas medievales a la hora de representar la Muerte. (1997, p. 111).
\end{abstract}

A hipótese da relação entre os temas macabros e a Peste Negra poderia ser verificada ainda, na Danza General, pelas armas usadas pela Morte. Na estrofe do poema reproduzida acima, ela usa seu arco e sua flecha "cruel, transpassante" (v. 8) contra todos, uma metáfora que não passaria despercebida pelo leitor da época. Conforme Jean Delumeau, a "chuva de flechas abatendo-se de súbito sobre os homens enviada do alto por um Deus encolerizado" era uma imagem recorrente entre os artistas do fim da Idade Média para representar a peste (2009, p. 163). Delumeau cita vários exemplos dessa iconografia, como um afresco de B. Gozzoli em San Gimignano (1464), um díptico de Martin Schaffner (ca. 1510-4) conservado em Nuremberg, entre outros. Uma variação desse tema "faz passar a flecha da mão de Deus para a da Morte":

\footnotetext{
Esqueleto cheio de esgares e por vezes galopando sobre os cadáveres, ela arremessa suas armas sobre os vivos de todas as condições, ocupados em trabalhar ou em divertir-se. (...) O que os artistas queriam também acentuar, além do aspecto da punição divina, era a instantaneidade do ataque do mal e o fato de que, rico ou pobre, jovem ou velho, ninguém podía vangloriar-se de a ele escapar - dois aspectos da epidemia que impressionaram vivamente todos aqueles que viveram em períodos de peste. (DELUMEAU, 2009, p. 163-4)
}

Essa simbologia também ganha popularidade no tema do "Triunfo da Morte", contemporâneo às danças macabras, que representa a Morte soberana e brutal, arrasando a humanidade por onde passa - e que a Danza General claramente evoca. No poema, ela 
é senhora do destino de toda gente, ela "aperta" suas vítimas (v. 375), tem a "mão dura" (verso 221) e "duros dentes" (v. 159). Sua dança queima como fogo (v. 176), é "esquiva" (v. 51), "baixa" (v. 138), uma dança "negra, repleta de choro" (v. 235). Todas as passagens indicam o sofrimento físico inflingido ao corpo na hora do trespasse, que apavoram e remetem à aniquilação da matéria, tão presente na memória relativa às devastações causadas pela peste.

Esse modus operandi não se aplica a todos os personagens. Morrer "de velhice", por exemplo, é o destino do Ermitão. Considerando-se que a expectativa de vida no século XV era de cerca de $35 \operatorname{anos}^{8}$, falecer idoso era um dado excepcional. A faixa etária em que seria adequado encaixar essa fase da experiência terrena varia com a fonte, de acordo com Charles de la Roncière, podendo ser a partir dos 45 anos ou, se optarmos por focar nos “indivíduos veneráveis (...) os verdadeiro velhos que cristalizam verdadeiramente os sentimentos e as atitudes suscitadas pela idade avançada”, delimitaríamos entre 65-70 anos (RONCIÈRE In DUBY, 1990, p. 231). Segundo Jacques Le Goff e Nicolas Truong, a longevidade associava-se às ideias de prestígio e malignidade - esta, conferida às mulheres, "feiticeiras em potencial"; aquela aos homens, muito por conta do estilo de viver monástico, que permitia um viver mais longo, e devido à importância atribuída à ancestralidade e à tradição. (2006, p. 104).

Esse parece ser o caso do Ermitão, que alega ter passado a vida servindo a Cristo, morando em miséria no deserto, rezando constantemente, em contemplação e abstinência, alimentado-se apenas de ervas. Apesar da vivência devota, esperando o dia em que se unirá a Deus, o ancião admite temer o instante do óbito, ao que a Morte lhe responde que é o necessário a fazer. É dos poucos personagens que aceita de bom grado seu destino. O mesmo só acontece com o Monge, chamado de monge negro pela Morte, por ser da ordem beneditina e fazer uso do hábito na cor preta. Para eles, morrer não é punição, mas prêmio. O Monge não se assusta com a feiúra da algoz e louva sua chegada, pois significa o término de sua prisão na terra. "Do cárcer escuro, venho à claridade" (v. 413): é o que ele diz ao morrer. A Morte lhe garante que, se viveu conforme a regra, será recompensado. 


\section{A morte do Médico}

Além dessa leitura panorâmica da Danza General em busca dos elementos que fazem mais aguda a percepção da chegada da Morte, há, no poema, um personagem que nos parece importante para essa discussão, e no qual nos deteremos nesse momento. Trata-se do Médico (o "Físico"). É interessante observar como o poema desenvolve o encontro entre a ceifadora e quem, supostamente, teria conhecimentos e instrumental necessário para evitar as doenças ou tratar ferimentos, livrando-se dela ou pelo menos adiando o fim da vida.

Já em seu chamamento, a Morte identifica seu comportamento orgulhoso ou possivelmente arrogante diante da possibilidade de ser intimado ("llegad aca, Físico, que estades ufano"- v. 360). Na estrofe em que responde, logo no primeiro verso, a vítima se diz enganada por Avicena, nome ocidentalizado de Ibn Sina, famoso médico e filósofo persa que viveu entre 980 e 1037. A menção a Avicena é eloquente, pois era (ainda é) um dos nomes mais relevantes da história do desenvolvimento dos saberes e das práticas médicas. Foi autor de diversos textos, entre eles o fundamental "Cânone de medicina" (escrito por volta de 1020), espécie de enciclopédia organizada em 5 livros, traduzida para o latim em 1187, pelo toledano Gerardo de Cremona, que passou a ser amplamente utilizado por estudiosos da área médica já nos decênios seguintes e entrou para os currículos universitários europeus no século XIV. Foi um dos livros de medicina mais impressos nos séculos XV e XVI, ${ }^{9}$ continuando a ser referência e base dos estudos médicos tanto no Ocidente quanto no Oriente, durante sete séculos (REBOLLO, 2010, p. 318).

A obra era um compêndio completo de todo o conhecimento médico que se tinha na época e passava por conteúdos diversos como a descrição do corpo, faculdades mentais e temperamento, práticas de higiene preventiva, descrições e causas das doenças, tratamentos, dietas apropriadas, influência do clima, farmacologia e botânica, administração e composição de medicamentos, diagnósticos e prognósticos, entre outros tópicos. O Médico da Danza General cita contribuições importantes de Avicena presentes nessa obra, em especial no Livro I, referentes ao dormir e ao comer: o entendimento de que o sono é um fenômeno fisiológico de recuperação do corpo, sendo necessário cumpri-lo por um determinado intervalo de tempo, mas sem excessos, deitar 
cedo e com a digestão avançada. Em relação à alimentação, aconselhava a eleição de certas comidas e bebidas de acordo com a idade, que deviam ser preparadas com os cuidados apropriados de limpeza e consumidas sem exageros (TEJEDA et al, 2016). Tanto é assim, que no poema, diz:

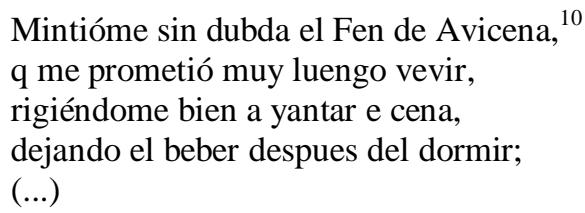

De acordo com a continuação da estrofe, a expectativa do Médico da Danza General, era mais garantir uma vida longeva para conquistar riquezas "curando os enfermos" do que para seu bem-estar. Com a chegada inesperada do fim, mesmo ele que domina os saberes do corpo e come e bebe com moderação, realiza que se faz obrigatório sofrer o trespasse e que "convém sofrer".

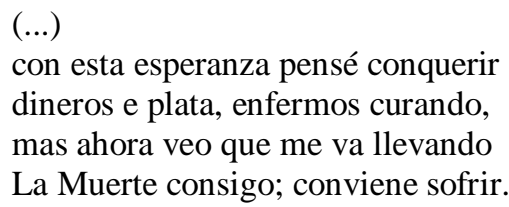

A réplica da Morte põe em cena Galeno e Hipócrates, aqueles que, ao lado de Avicena, completam a tríade do pensamento médico medieval. "Dom” Hipócrates (460377 a. C.), como a Morte respeitosamente o chama, é o médico grego, ao qual foi atribuída a teoria dos humores (sangue, fleuma, bile amarela e bile negra), que supõe como causa das patologias um desequilíbrio entre eles e na qual se baseia grande parte do entendimento medieval sobre as doenças (LE GOFF e TRUONG, 2006, p. 109-10). Foi autor de inúmeras obras, sendo o tratado Aforismos, seu texto mais conhecido (citado na Danza como "inforismos"), que sintetiza o conhecimento dos antigos médicos gregos e foi concebido para a memorização e a prática (REBOLLO, 2010, p. 318). Já Galeno foi o médico e filósofo grego que viveu entre 129 d.C. e 216 d.C., profundamente influenciado por Hipócrates (cuja leitura, segundo Le Goff e Truong, combina com a de Aristóteles [2006, p. 111]), célebre por suas contribuições sobre anatomia e medicina empírica (ele realizava dissecações em animais). O último verso pronunciado pelo Médico, em que se prepara para sofrer, poderia ser uma referência a 
Galeno e sua luta ativa contra o sofrimento e a doença, sua preocupação com a dor inflingida ao corpo durante os tratamentos, noção que os médicos medievais tentaram praticar, inclusive criando métodos anestésicos, técnicas que não funcionavam com eficácia mas que evidenciavam que "contrariamente à ideia segundo a qual a Idade Média fazia pouco do sofrimento físico, a medicina medieval buscou meios para atenuálo" (LE GOFF e TRUONG, 2006, p. 115).

A dupla de gregos pavimentou o pensamento desenvolvido por Avicena no Cânone, daí a inclusão dos três na Danza. Não seria a primeira vez que os três nomes apareceriam juntos em uma obra poética: na Divina Comédia, de Dante Alighieri, o verso 143 do Canto IV, é inteiramente dedicado a eles. A despeito de terem sido colocados no Limbo, na entrada do Inferno, por não conhecerem o cristianismo, foram homens de virtude e, por isso, são tratados com reverência pelo poeta florentino. Na Danza General, a Morte os evoca como partícipes do repertório do médico:

\footnotetext{
Pensastes vos, Físico, que por Galeno o don Hipocrás, con sus inforismos, seríades librado de comer del feno, que otros gastaron de más sologismos; (..)
}

$\mathrm{Na}$ lógica da Morte, a proximidade com Galeno e com os aforismos de Hipócrates, não livraria o Médico de "comer do feno"- o que, na edição crítica do poema feita por Josep Sola-Sole, seria uma metáfora para "fenecer rapidamente", não apenas utilizando o jogo de palavras com feno/fenecer mas porque uma das características do feno é de secar (portanto, morrer) logo (1981, p. 247). Apelar aos conhecimentos dos dois mestres não dá mais vantagem ao médico que às outras vítimas que empregaram, inutilmente, "mais silogismos" para escapar do óbito. Na concatenação de sugestões sobre a formação do Médico, enunciada pela Morte, esta poderia indicar a inclusão do pensamento aristotélico, caracterizado pelo silogismo. Assim, fecharia-se o circuito referencial aos quatro filósofos pilares para a educação médica durante todo o período moderno (Aristóteles, Hipócrates, Galeno e Avicena). ${ }^{11}$

Conclamar as maiores autoridades da medicina praticada no período medieval nos versos da Danza General pode nos revelar alguns dados. O primeiro é que seu autor conhecia esses nomes e suas contribuições à área, o que talvez seja índice de seu lastro 
cultural $^{12}$ ou de que fossem, de fato, conhecidos no senso comum do medievo. $\mathrm{O}$ segundo é a afirmação, dentro do entendimento de uma religiosidade laica à qual provavelmente as danças macabras fizessem parte, de que todo conhecimento médico desenvolvido até então não era páreo para o poder supremo da Morte. Por fim, nos revelaria algumas das práticas correntes e baseadas na medicina para se combater os males do corpo: uma dieta equilibrada, o descanso e, quando necessário, gargarejos e xaropes.

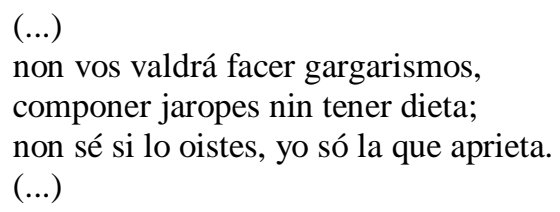

Ainda que não seja o nosso foco nesse artigo, cabe aqui um comentário acerca da versão impressa da Danza General de la Muerte, de 1520, feita em Sevilha, que escala, antes do Médico, um Cirurgião. Joseph Byrne nos lembra que a separação entre o cirurgião, que manipula o corpo humano, e o médico, quem observa, diagnostica e prescreve remédios e tratamentos, não veio da Antiguidade nem do Oriente: foi uma distinção criada pela cristandade ocidental. (2012, p. 333, verbete Surgeons/Barbers). Observe-se o que argumenta esse profissional ao ser interpelado pela Morte:

\footnotetext{
Oh, muerte señora, hazes sin razon, si assí improviso me has de llevar, ca soy necessario en toda sazon; segun mi oficio yo devo quedar. Lo que hace el físico, quasi es adevinar en la enfermedad que tiene el dolíente; mas lo que yo hago está claramente: muerte, yo te ruego quiérasme dexar. ${ }^{13}$
}

Chamamos a atenção para o trecho que insinua a importância do ofício do cirurgião em detrimento do médico, já que o que este faz é "adivinhar a enfermidade", enquanto que o segundo de fato "trata" o doente e livra-o da morte, sendo, portanto, mais necessário que aquele. Jacques Le Goff e Nicolas Truong falam da separação entre a cirurgia e a medicina por decisão papal através do Concílio de Tours, em 1163, e a posterior rixa entre essas corporações a partir do século XIV, com os surtos de Peste 
Negra, cujo avassalador contágio colocou em crise os respectivos ofícios (2006, p. 106).

E enfatizam as importantes inovações técnicas no domínio da cirurgia no período medieval, como a trepanação, redução das fraturas, operações de fístula anal, ligadura de hemorróidas, hemóstase por cauterização, extração de metais por imã e suturas de feridas no peito (idem, p. 118), o que talvez causasse a impressão de que era, efetivamente, o cirurgião que resolvia os males do corpo - sentimento que o Cirurgião da Danza ostenta orgulhosamente - ainda que, a rigor, seu status fosse inferior ao do médico. $^{14}$

Poderíamos, à guisa de ilustração, evocar uma outra dança macabra, das mais representativas para o gênero, a Danse macabre do editor francês Guyot Marchant, em sua edição de 1486, que representa o personagem do Médico segurando a matula (figura 1) - o recipiente de vidro específico para a uroscopia, o exame de urina, que se tornou a insígnia corporativa dos médicos (LE GOFF e TRUONG, 2006, p. 113). Além da observação a olho nu, feita pela visualização do frasco com o líquido contra a luz, era realizada a avaliação do cheiro e do sabor. Dos textos médicos que apontavam a relevância da análise da urina para o diagnóstico e o prognóstico das enfermidades, estavam justamente os Aforismos de Hipócrates e o Livro 1 do Cânone de Avicena. No impresso de Marchant, enquanto vai sendo puxado por um morto e empurrado por outro, o Médico examina sua própria urina e chega à conclusão de que "contra a morte, não há remédio". ${ }^{15}$ 


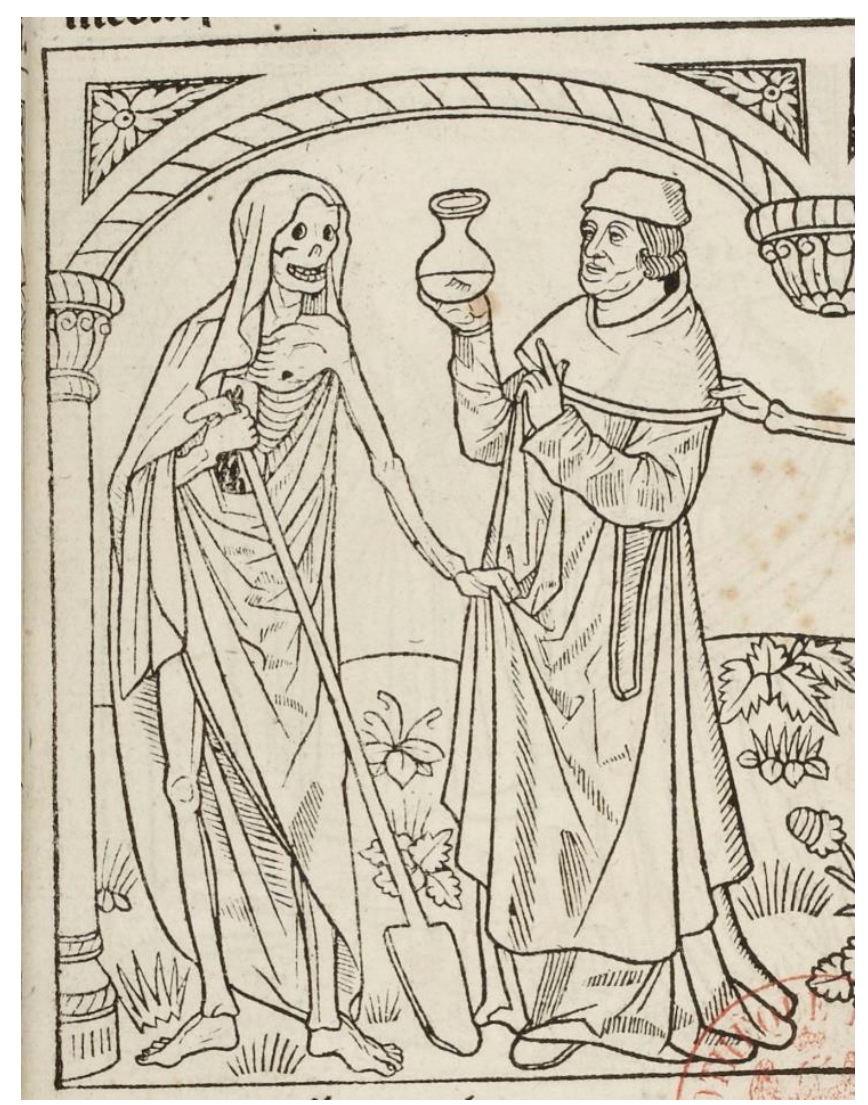

Figura 1: um morto e o médico. Detalhe de xilogravura na Danse macabre de Guyot Marchant, impressa em Paris em 1486. Fonte: Biblioteca Nacional da França. Disponível em:

https://gallica.bnf.fr/ark:/12148/btv1b8615802z/f23.item.r=miroir\%20salutaire\%201486

\section{"Fácenme danzar danza de dolores": considerações finais}

A Danza general de la Muerte revela aspectos de um período que concentra suas atenções na perecibilidade do corpo e em seus aspectos perturbadores: a putrefação das carnes, os líquidos viscosos, o mal-cheiro, os parasitas que darão cabo da matéria infecta. A dor e o sofrimento no momento do óbito aparecem como premissas desses desdobramentos do post-mortem, daí vermos a insistência com que a "dança", no poema, é caracterizada como um evento de tormentos físicos compulsórios. É o que aparece na estrofe em que fala o Escudeiro quando sente que vai morrer:

Dueñas e doncellas, habed de mí duelo, fácenme por fuerza dejar los amores; echóme la Muerte su sotil anzuelo, fácenme danzar danza de dolores; non traen por cierto firmalles nin flores, los que en ella danzan, mas gran fealdad. (...) 
"Dança de dores" (v. 268), "dança sem piedade" (v. 154), "dança do choro" (v. 296): como já comentamos, são muitas as expressões do poema que qualificam o instante da morte como de angústia e penar. Pudemos demonstrar em nosso artigo, as variadas formas como a fisicalidade do morrer se coloca reiteradas vezes em suas estrofes. A perda dos sentidos e da consciência, alteração da sensação corpórea, a aparição de inchaços e tumores são alguns dos sinais percebidos como parte do processo do trespasse. O poema sugere, no entanto, que ele não precisaria ser traumático, pois há o caso dos homens que se dedicaram verdadeiramente à fé e se afastaram das tentações do mundo: o Monge e o Ermitão. Eles se entregam à Morte como se ela fosse uma libertação, a vitória do espírito sobre a matéria.

O personagem do Médico, por sua vez, oferece pistas para nossas compreensão sobre as tentativas de controlar os males do corpo, as providências tomadas para fortalecê-lo e o conhecimento da época para deter as enfermidades. A mensagem que fica, ao fim, é que são todos em vão pois o poder da Morte é maior que o do homem.

A preocupação do gênero das danças macabras em colocar essas figuras diversas pertencentes à sociabilidade medieval reagindo à chegada da morte mostra seu ensinamento bastante pedagógico da intransponibilidade do fim. Às vésperas da modernidade, as danças aparecem como evidência de uma sensibilidade crescentemente mais apurada do medievo para sua própria condição física, seus limites, suas fraquezas e potências no crucial instante do último suspiro.

\section{Bibliografia}

ARIÈS, Philippe. História da morte no Ocidente. Da Idade Média aos nossos dias. Tradução Priscila Viana de Siqueira. Rio de Janeiro: Ediouro, 2003.

AVICENNA. The influence of Avicenna on medical studies in the West. In Encyclopædia Iranica, III/1， pp. 107-110. Disponível online em http://www.iranicaonline.org/articles/avicenna-xiii

BYRNE, Joseph P. Encyclopedia of the Black Death. ABC-CLIO, 2012. 
CORVISIER, André. Les danses macabres. Collection Que sais-je?. Paris: Presses Universitaires de France, 1998.

CORVISIER, André. La représentation de la société dans les danses des morts du XVe au XVIIIe siècle. In: Revue d'Histoire Moderne et Contemporaine. Tome XVI, octobre-décembre 1969, p. 489-539.

DELUMEAU, Jean. História do medo no Ocidente. 1300-1800: uma cidade sitiada. Tradução Maria Lucia Machado. São Paulo: Companhia das Letras, 2009.

HERRERO, M. Nieves Sanchez e BENITO, M. Concepción Vázquez de. "La huella de Avicena em La medicina medieval castellana”. In: CLAVERIA, G. ESCRIBANO, C.G., JULIÀ, C. et al. (orgs). Historia, lengua y ciencia, una red de relaciones. Frankfurt AM Main: Peter Lang. 2013.

HUIZINGA, Johan. O outono da Idade Média. Estudo sobre as formas de vida e de pensamento dos séculos XIV e XV na França e nos Países Baixos. Tradução Francis Petra Janssen. São Paulo: Cosac Naify, 2010.

HURTADO, Haydée Bermejo y CVITANOVIC, Dinko. Danza General de la Muerte. Bahía Blanca: Cuadernos del Sur, 1966.

INFANTES, Víctor. Las danzas de la muerte. Génesis y desarrollo de un género medieval (siglos XIII-XVII). Salamanca: Ediciones Universidad de Salamanca, 1997.

LE GOFF, Jacques e TRUONG, Nicolas. Uma história do corpo na Idade Média. Tradução Marcos Flamínio Peres. Rio de Janeiro: Civilização Brasileira, 2006.

REBOLLO, Regina Andrés. A Escola Médica de Pádua: medicina e filosofia no período moderno. In: Manguinhos - História, Ciências, Saúde. Rio de Janeiro, v.17, n.2, abr.-jun. 2010, p. 307-331. Disponível online em https://www.scielo.br/pdf/hcsm/v17n2/03.pdf Acesso em 05 de junho de 2020.

RONCIÈRE, Charles de la. A vida privada dos notáveis toscanos no limiar da Renascença. In: DUBY, Georges. História da vida privada 2: da Europa feudal à Renascença. Tradução Maria Lúcia Machado. São Paulo Companhia das Letras, 1990.

SAUGNIEUX, Joël. Les danses macabres de France et d'Espagne et leurs prolongements littéraires. Paris: Société d'Édition “Les Belles Lettres”, 1972. 
SCHMITT, Jean-Claude. A morte na Idade Média cristã. In: GODELIER, Maurice (org). Sobre a morte: inveriantes culturais e práticas sociais. Tradução Edgar Assis Carvalho e Mariza Perassi Bosco. São Paulo: Edições Sesc, 2017, p. 153-72.

SCHMITT, Juliana. O imaginário macabro: Idade Média - Romantismo. São Paulo: Alameda, 2017.

SOLÁ-SOLÉ, Josep M. La Dança General de la Muerte. Edición crítica, analítico-cuantitativa. Barcelona: Puvill Editor, 1981.

TEJEDA, F.I.A.; ACOSTA, Y.D.; RAMOS, A. T. M.; CORRÍA, B.R. e PÉREZ, Carlos Benítez. "Avicena y la transcendencia de la medicina y la cultura islâmicas en el mundo occidental.” In: Edumecentro. N.8 (suppl 2), 2016, p. 32 -47.

TENENTI, Alberto. Il senso della morte e l'amore della vita nel Rinascimento (Francia e Italia). Giulio Enaudi Editore, 1957.

\section{Notas}

\footnotetext{
${ }^{1}$ Por um critério de padronização das citações, todas as referências ao poema usadas nesse artigo são retiradas da edição do texto publicada como: La Danza de la Muerte. Códice del Escorial, grabados de Holbein. Edición y prólogo de F.A. de Icaza. Madrid: Imprenta de Fortanet, 1919. Ao contrário das outras edições às quais tivemos acesso (todas listadas na Bibliografia), esta realiza a modernização da grafia das palavras do poema, tornando mais inteligível seu conteúdo.

${ }^{2}$ Isso porque o manuscrito possui a indicação de ser uma "trasladación" - ainda que não fique claro o que exatamente isso significa, podendo ser uma tradução, uma adaptação ou uma mera transferência (cópia) de um texto anterior.

3 A discussão sobre a datação do manuscrito é profícua, não havendo um consenso entre os pesquisadores, que sugerem datas entre o fim do século XIV e o fim do XV. Para citar apenas alguns exemplos, evocamos Josep Sola-Sole (1981) e Victor Infantes (1997) que defendem que a caligrafia de tipo gótica e o uso do $h$ supérfluo em palavras como handar, hedad, thener, etc, seriam característicos do fim do XIV até meados do XV, ainda que para Infantes, sua periodização mais provável seja princípios dos 1400. Essa é também a aposta de Jöel Saugnieux (1972). Para Solá-Solé, a presença de um personagem denominado "rabino Açá" também oferece pistas: o pesquisador o identifica como sendo Yishaq ben Seset Perfet (1326-1408), personalidade famosa à época, cuja perseguição pelo pogrom de 1391 teria causado grande comoção na comunidade judaica. A partir daquela data, o nome do rabino seria bastante popular, o que teria influenciado o autor da dança a incluí-lo entre os personagens - resultando, assim, na estimativa de sua produção como sendo daqueles anos (fim do XIV, início do XV). Johan Huizinga (2010) é uma voz dissonante, datando o documento no fim do século XV. Concluindo pela incerteza dessas aproximações, Francisco Oquendo chama a atenção para o caráter deítico de vários dos seus versos, que aprisionam nas brumas uma série de colocações do poeta, pois suas informações imprecisas dificultam sua contextualização. (Danza...., 1983). Para além da discussão sobre a data de confecção do manuscrito, há ainda o debate sobre sua natureza de documento original ou de cópia de uma versão anterior. Todos os autores referendados acima abordam a questão e, novamente, não existe unanimidade.

${ }^{4}$ Ver em SCHMITT, Juliana. O imaginário macabro: Idade Média-Romantismo. São Paulo: Alameda, 2017.

${ }^{5}$ Ainda que sua datação exata fosse um pouco anterior ou um pouco posterior ao século XV, o documento faz parte do contexto de desenvolvimento do gênero das danças macabras. Ou, como diria Ariès:
} 
"Quando se fala em temas macabros, pensa-se espontaneamente no século XV, um pouco antes, um pouco depois, porque é nesta época que os historiadores os localizaram e analisaram, e foi para compreender esta época que os interpretaram." (2003, p. 139).

${ }^{6}$ Segue transcrição da estrofe completa: "Qué loucura es ésta tan magnifiesta?/Qué piensas tu, homne, que el outro morra/e tu quedarás, por ser bien compuesta/la tu complisión, e que durarás?/Non eres cierto, si en punto verná/sobre ti a deshora alguna corrupción,/de landre o carbonco o tal implisión,/porque el tu vil cuerpo se desatará." (La Danza de la Muerte..., 1919, p. 19).

${ }^{7}$ Huizinga menciona essa questão do gênero nas danças macabras (2010, p. 236); de nossa parte, abordamos o tema no artigo "Venez dames et demoiselles: a Danse macabre des femmes e a presença feminina na Baixa Idade Média". Revista Todas as Musas. Ano 7, número 2, jan-jun 2016.

${ }^{8}$ Fizemos a média entre a informação obtida em Le Goff e Truong ("Com frequência, os historiadores com formação em demografia estimam que a esperança de vida se situava, em média, entre trinta e cinco e quarenta anos.") com o que nos informa Jean-Claude Schmitt: "calcula-se que entre o século XI e a metade do século XIII, a expectativa de vida chegava aos 35 anos. Desde o fim do século XIII, ela teria até mesmo baixado para cerca de 30 anos, em razão de perturbações profundas no ecossistema que abrangeu toda a Europa (...) isso tudo antes mesmo da agressão brutal da peste negra, que ocorreu de 1348 a 1351.” (LE GOFF e TRUONG, p. 93; SCHMITT In GODELIER, 2017, p. 154).

9 Ver todo o verbete AVICENNA, na Encyclopadia Iranica, III/1, pp. 107-110. Disponível em http://www.iranicaonline.org/articles/avicenna-xiii (Acesso em 25 de setembro de 2020).

${ }^{10}$ Fen seria a transcrição do termo árabe fann, significando capítulo ou divisões no texto dos livros que compõe o Cânone. (HERRERO e BENITO In: CLAVERIA et al., 2013, p. 262). No caso do verso da Danza general, o médico se refere à parte do livro de Avicena que ensina um "longo viver", com atenção à dieta e ao dormir.

${ }^{11}$ Regina Andrés Rebollo fez um levantamento do programa curricular da Universidade de Pádua, considerada o melhor centro europeu para o estudo da medicina, nos séculos XVI e XVII. Observou que a formação médica do período passava pelo estudo dos autores considerados clássicos: Hipócrates, Galeno, Avicena e Aristóteles - este, a partir dos seissentos. (REBOLLO, 2010, p.307-331)

${ }^{12}$ Essa é a hipótese de André Corvisier (1998, p. 81) e de Victor Infantes (1997, p. 241), que defendem que o autor da Danza general seja alguém de alto nível intelectual.

${ }^{13}$ Citado conforme reprodução do poema em SAUGNIEUX, Jöel. Les danses macabres de France et d'Espagne et leurs prolongements littéraires. Paris: Le Belles Lettres, 1972, p. 194.

${ }^{14}$ Menos em um lugar, em Edinburgo, com sua Guilda de Barbeiros-Cirurgiões - é o que afirma Joseph Byrne (2012, p. 333, verbete Surgeons/Barbers).

${ }^{15} \mathrm{Na}$ Danse macabre de Guyot Marchant, as xilogravuras são de Pierre Le Rouge e o poema, atribuído a Jean Gerson. "Contre la mort n’a médicine”é o último verso da estrofe em que fala o Médico. 